\title{
Acculturation and the oral health of a nationally representative sample of Hispanic children in the United States: an analysis of 2011-2012 National Survey of Children's Health data
}

\author{
Faizan A. Kabani ${ }^{1 \dagger}$, Erica L. Stockbridge ${ }^{2,3^{*}+}$ (D), Bibi Berly Varghese ${ }^{2,4}$ and Abiah D. Loethen ${ }^{3}$
}

\begin{abstract}
Background: Oral disease is a serious public health issue, and Hispanic children in the United States (US) are more likely than children of other racial/ethnic groups to experience dental caries. Although Hispanic children are a growing segment of the US population there is limited research on the association between acculturation and oral health outcomes in this population. This study examined the associations between household acculturation and pediatric oral health in the Hispanic population using a nationally representative sample of children.

Methods: Data from the 2011-2012 National Survey of Children's Health were analyzed; analyses included Hispanic children ages 1 to 17. Household acculturation was assessed with a combination of language and parental nativity, while oral health was assessed via parents'/guardians' reports of children's dental caries. Logistic regression was used to examine the association between acculturation and oral health, adjusting for other demographic and social determinants of pediatric oral health. We assessed significance at the $p<0.05$ level, and all analyses accounted for the survey's complex sample design.

Results: Analyses included 9143 Hispanic children. In total, 24.9\% (95\% Cl: 22.9-27.0\%) experienced dental caries, and there were significant associations between household acculturation and oral health. In unadjusted analyses, $32.0 \%$ (95\% Cl: 28.9-35.4\%) of children in low acculturation households, $20.3 \%$ (95\% Cl: 16.0-25.4\%) of children in moderate acculturation households, and 16.9\% (95\% Cl: 14.2-20.0\%) of children in high acculturation households experienced dental caries $(p<0.001)$. In adjusted analyses, children in high acculturation households were significantly less likely than those in low acculturation households to experience dental caries $(p<0.001 ; \mathrm{OR}=0.50$; 95\% Cl: 0.35-0.70). The difference between children in moderate and low acculturation households approached but did not reach statistical significance ( $p=0.057 ; \mathrm{OR}=0.69 ; 95 \% \mathrm{Cl}: 0.48-1.01$ ).

(Continued on next page)
\end{abstract}

\footnotetext{
* Correspondence: Erica.Stockbridge@unthsc.edu

${ }^{\dagger}$ Faizan Kabani and Erica L. Stockbridge contributed equally to this work.

${ }^{2}$ Department of Health Behavior and Health Systems; School of Public

Health, University of North Texas Health Science Center, 3500 Camp Bowie

Blvd, Fort Worth, TX 76107, USA

${ }^{3}$ Department of Advanced Health Analytics and Solutions; Magellan Health,

Inc., 4800 N. Scottsdale Rd. \#4400, Scottsdale, AZ 85251, USA

Full list of author information is available at the end of the article
}

(c) The Author(s). 2020 Open Access This article is distributed under the terms of the Creative Commons Attribution 4.0 International License (http://creativecommons.org/licenses/by/4.0/), which permits unrestricted use, distribution, and reproduction in any medium, provided you give appropriate credit to the original author(s) and the source, provide a link to the Creative Commons license, and indicate if changes were made. The Creative Commons Public Domain Dedication waiver (http://creativecommons.org/publicdomain/zero/1.0/) applies to the data made available in this article, unless otherwise stated. 
(Continued from previous page)

Conclusions: A dose-response relationship was observed between household acculturation and the oral health of Hispanic children in the US. As acculturation increases, the likelihood of a child experiencing dental caries decreases. These findings suggest that public health and community-based interventions intended to reduce oral health disparities in Hispanic children would likely be most impactful if the acculturation levels of the children's households are considered during program development.

Keywords: Oral health, Dental caries, Acculturation, Social determinants, Pediatric health, Hispanic, Latino, Children, Disparities

\section{Background}

Hispanic children are a growing segment of the United States (US) population. The percentage of children in the US who are Hispanic has increased from $17 \%$ in 2000 to $25 \%$ in 2016 [1], and nearly a third of Hispanics in the US are under age 18 [2]. The oral health of Hispanic children is of concern, as they are more likely than children of other racial and ethnic groups to experience dental caries (i.e., tooth decay) [3]. Dental caries are associated with orofacial pain and decreased oral-healthrelated quality of life and, when untreated, caries lead to tooth loss and systemic infection [4]. Oral diseases are considered a major public health issue because of their high prevalence and their negative effects on well-being [5]. Over time, oral health problems may lead to or exacerbate other health conditions including endocarditis, cardiovascular disease, premature birth, and low birth weight [6]. Further, children's self-esteem [7], school attendance, and ability to communicate are negatively affected by poor oral health [8].

As slightly over one-third of Hispanics in the US are immigrants [1], many Hispanic children reside in households experiencing acculturation. Acculturation is a process involving a shift in attitudes, behaviors, and identity that occurs as persons or groups from different cultural backgrounds come into contact with one another, and it is most often examined in terms of immigrants' adaptation to a new society $[9,10]$. As immigrants become acculturated, their health status may improve or worsen depending on the health condition of interest, the new environments to which the immigrants are exposed, and the adoption of the host country's normative dietary, physical activity, and other health-related behaviors. Accordingly, changes in oral health are associated with acculturation [11]. A sizable body of research on Hispanic adults suggests that acculturation typically improves the oral health outcomes of this population [11]. Higher levels of acculturation in Hispanic adults in the US are generally associated with a decreased likelihood of orofacial pain [12], dental caries [13-15] and periodontal disease [13, 14, 16-18], although findings related to oral health-related quality of life are inconsistent $[19,20]$.

Conversely, there is limited research on the association between acculturation and oral health outcomes in
Hispanic children in the US. A recent review of the literature on acculturation and oral health identified only four studies examining oral health outcomes in Hispanic children [11], and those studies had significant limitations. Three of the four were based on convenience samples [21-23], and none included children of all ages and dentition categories [24] nor were they nationally representative of Hispanic children from across the US [14, 21-23]. Our own investigation of the literature identified no additional studies on oral health outcomes in Hispanic children. The few studies on oral health and acculturation in children suggest that oral health outcomes generally improve as acculturation increases [14, 21-23], but due to the serious limitations of these studies additional research is needed to confirm these findings.

Given the large and growing number of Hispanic children in the US [2], the associations between acculturation and oral health in Hispanic adults [12-14, 16, 17], and the effects of pediatric oral health on quality of life and other aspects of health [6-8], the limited research on oral health outcomes in Hispanic children is a concern. The current study fills this important research gap. The objective of this study was to examine the associations between household acculturation and pediatric oral health in the Hispanic population using a nationally representative sample of children and including children ages 1 to 17 from all dentition categories (i.e., primary, transitional, and permanent [24]). Results of this study can be used by community interventionists and other dental program personnel to develop, implement, and evaluate programs intended to reduce oral health disparities of Hispanic children of all age groups who reside in households with varying levels of acculturation.

\section{Methods}

This project was reviewed and approved as expedited category research by the Institutional Review Board of the Office of Research Compliance at the University of North Texas Health Science Center.

\section{Data Source \& Analytic Sample}

We analyzed data from the 2011-2012 National Survey of Children's Health (NSCH), a survey sponsored by the 
Maternal and Child Health Bureau of the US Health Resources and Services Administration. NSCH examines the physical and emotional well-being of children residing in the US who are between the ages of 0 and 17, and $\mathrm{NSCH}$ data are nationally representative of noninstitutionalized children when weighted and adjusted for the complex sample design. NSCH data contain health-related information about one randomly selected child per sampled household. These data were collected using telephonic interviews of a parent or guardian who was knowledgeable about the healthcare use and health status of the selected child. The 2011-2012 NSCH data included 95,677 child-level interviews [25].

Our analyses included Hispanic children ages 1 to 17; $\mathrm{NSCH}$ does not evaluate the presence of dental caries in children younger than 1 year. Additionally, children with missing data on the variables described below were excluded from the analysis.

\section{Measures}

\section{Outcome variable}

The outcome of interest was oral health as measured by the presence of dental caries, as ascertained with the question "During the past 12 months did [child's name] have a toothache, decayed teeth, or unfilled cavities?" We considered a response of "Yes" to be indicative of dental caries. We selected this variable as the outcome variable because oral health status in pediatrics is largely surveyed via dental caries indices and protocols [26].

\section{Primary explanatory variable}

The primary explanatory variable was household acculturation. As NSCH did not directly assess acculturation, we generated a proxy variable by combining information from three other variables: primary language in the household, language in which the interview was conducted, and generational status of the household. Our acculturation variable categorized children into low, moderate, and high household acculturation groups. The low acculturation group consisted of children who resided in a household in which the primary language was not English or the NSCH interview was conducted in a language other than English and the child had at least one foreign-born parent (i.e., first- and secondgeneration households). The high acculturation group consisted of children who resided in a household in which the primary language was English, the NSCH interview was conducted in English, and the children's parents were US-born (i.e., third- or higher generation households). The moderate acculturation group consisted of those not falling into either of the prior two categories. Thus, this group consisted of children in households in which a response to a language-related variable suggested that English was not the preferred language and their parents were born in the US, and it also included children for whom responses to both language-related variables suggested a household preference for English and the child had at least one foreign-born parent.

Our measure of acculturation aligns with past research indicating that, in Hispanic youth, there is a marked shift in socialization and acculturation between the second and third generations [27]. Additionally, while we identified no previous study that used an identically constructed variable to assess household acculturation, our approach is consistent with that of several previous studies that also examined the association between oral health and acculturation. Like our method, these studies utilized a combination of variables to capture the extent of acculturation in minority and immigrant populations $[11,28,29]$, including household primary language, generational status, nativity status, age at immigration, length of stay, country of birth, and ethnic identification $[11,28]$. Our combined measure of language and generational status serves as a reasonable proxy measure of acculturation given that there are strong associations between generational status, language, and acculturation [30]; in fact, generational status and language are included as components of a variety of acculturation measurement tools designed for the Hispanic population [31].

\section{Explanatory covariates}

Additional variables were included in our statistical model to adjust for potential confounders in the relationship between dental caries and household acculturation. These covariates consisted of demographic and social determinants of pediatric oral health as identified by da Fonseca and Avenetti [32]. Specifically, we included age (categorized based on dentition status [24]), sex, race, federal poverty level, parental/guardian educational status, presence of health insurance, neighborhood maintenance, household structure (i.e., two parents, one parent and one stepparent, single mother, other), number of children in household, neighbors' helpfulness, special healthcare needs of the child, parental/guardian health status, and whether the child visited a dentist in the previous 12 months.

\section{Statistical analyses}

First, we determined the number of people in each category of the explanatory variables and conducted Pearson's chisquare tests to examine the unadjusted relationships between the explanatory variables and the likelihood of a child having dental caries. Next, we explored the adjusted association between household acculturation and childhood dental caries using a multiple logistic regression model [33]. We then used the model to estimate the adjusted probability of having dental caries at each level of household acculturation. We calculated these probabilities based on the 
average predicted probability of having dental caries conditional on all observations having a given value of the household acculturation variable, and we expressed the results as percentages.

We conducted all analyses in Stata ME version 14.1 (College Station, Texas) and assessed significance at the $p<0.05$ level. All analyses accounted for the complex survey design of the $\mathrm{NSCH}$.

\section{Results}

A total of 9143 children met the inclusion criteria for the study. After weighting and adjusting for complex sample design, these children represented 11,728,637 Hispanic children from across the US. In total, 24.9\% (95\% CI: 22.9-27.0\%) of the children experienced dental caries. These children were categorized into household acculturation levels based on language and generational status based on the logic described previously; information on the observed counts and weighted proportion of children at each level of the language and generational status variables are provided in Table 1. Low levels of acculturation were observed in $49.3 \%$ (95\% CI: 46.9-51.6\%) of Hispanic children. Children in moderate and high acculturation households represented 16.4\% (95\% CI: 14.8-18.1\%) and $34.4 \%$ (95\% CI: $32.2-36.6 \%$ ) of the children, respectively.

\section{Dental caries and acculturation}

There were significant associations between household acculturation and dental caries in both unadjusted and adjusted analyses. Table 2 contains the unadjusted bivariate analyses examining the association between dental caries and other variables of interest, including confidence intervals. In unadjusted analyses, the likelihood of dental caries decreased as household acculturation increased. Specifically, $32.0 \%$ of children in low acculturation households experienced dental caries, $20.3 \%$ of children in moderate acculturation households experienced dental caries, and $16.9 \%$ of children in high acculturation households experienced dental caries $(p<$ $0.001)$.

Table 3 contains the results of the logistic regression model examining the adjusted association between household acculturation and childhood dental caries, including odds ratios. In adjusted analyses, a doseresponse relationship was observed between acculturation and dental caries (see Fig. 1). Children in high acculturation households were significantly less likely than those in low acculturation households to experience dental caries $(p<0.001)$. The difference between children in moderate and low acculturation households approached but did not reach statistical significance $(p=$ 0.057). The average predicted probabilities of dental caries in the high, medium and low acculturation households were $29.5,23.2$, and $18.3 \%$, respectively.

\section{Explanatory covariates}

Detailed results of the unadjusted and adjusted analyses examining the associations between dental caries and the explanatory variables can be found in Tables 2 and 3 , respectively. Neither sex nor race were significantly associated with dental caries in unadjusted nor adjusted

Table 1 Cross-tabulation of the generational status of households and language use, based on data from the National Survey of Children's Health, 2011-2012, for Hispanic children in the US. The generational status and language variables were used to categorize children into low, moderate, and high household acculturation levels as shown below. The estimated percentages and estimated Ns account for the weighting and complex survey design of the NSCH and are thus nationally representative, while the observations do not account for weighting or complex survey design

\begin{tabular}{|c|c|c|c|c|c|}
\hline \multirow[t]{2}{*}{ Language } & \multirow[t]{2}{*}{ Measure } & \multicolumn{3}{|c|}{ Generational Status of Household } & \multirow[t]{2}{*}{ Totals } \\
\hline & & 1st Generation & 2nd Generation & 3rd or Higher Generation & \\
\hline \multirow{4}{*}{$\begin{array}{l}\text { English was not the } \\
\text { primary language in } \\
\text { the household or the } \\
\text { survey was taken in a } \\
\text { language other than } \\
\text { English }\end{array}$} & Acculturation Categorization & Low & Low & Moderate & - \\
\hline & Estimated \% of Population & $7.9 \%$ & $41.4 \%$ & $2.5 \%$ & $51.8 \%$ \\
\hline & Estimated $\mathrm{N}$ in Population & 927,178 & $4,852,472$ & 293,391 & $6,073,041$ \\
\hline & Observations in Sample & 563 & 2847 & 165 & 3575 \\
\hline \multirow{4}{*}{$\begin{array}{l}\text { English was the primary } \\
\text { language in the household } \\
\text { and the survey was taken } \\
\text { in English }\end{array}$} & Acculturation Categorization & Moderate & Moderate & High & - \\
\hline & Estimated \% of Population & $0.2 \%$ & $13.6 \%$ & $34.4 \%$ & $48.2 \%$ \\
\hline & Estimated $\mathrm{N}$ in Population & 27,727 & $1,598,506$ & $4,029,363$ & $5,655,596$ \\
\hline & Observations in Sample & 25 & 1453 & 4090 & 5568 \\
\hline \multirow[t]{4}{*}{ Totals } & Acculturation Categorization & - & - & - & - \\
\hline & Estimated \% of Population & $8.1 \%$ & $55.0 \%$ & $36.9 \%$ & $100.0 \%$ \\
\hline & Estimated $\mathrm{N}$ in Population & 954,905 & $6,450,978$ & $4,322,754$ & $11,728,637$ \\
\hline & Observations in Sample & 588 & 4300 & 4255 & 9143 \\
\hline
\end{tabular}


Table 2 Unadjusted associations between dental caries and characteristics of Hispanic children residing in the United States (unweighted $n=9143$ )

\begin{tabular}{|c|c|c|c|c|}
\hline & \multirow{2}{*}{$\begin{array}{l}\text { Total Sample } \\
\text { (Column \%) }\end{array}$} & \multicolumn{2}{|c|}{ Dental Caries in Past Year (Row \%) } & \multirow[t]{2}{*}{$p$-value } \\
\hline & & Had Dental Caries & No Dental Caries & \\
\hline Unweighted N & $n=9143$ & $n=2019$ & $n=7124$ & \\
\hline Total Sample of Hispanic Children & 100 & $24.91(22.9,27.0)$ & $75.10(73.0,77.1)$ & - \\
\hline \multicolumn{5}{|l|}{ Acculturation Group } \\
\hline Low Acculturation & $49.28(46.9,51.6)$ & $32.03(28.9,35.4)$ & $67.97(64.6,71.1)$ & \multirow[t]{3}{*}{$<0.001$} \\
\hline Moderate Acculturation & $16.37(14.8,18.1)$ & $20.31(16.0,25.4)$ & $79.69(74.6,84.0)$ & \\
\hline High Acculturation & $34.35(32.2,36.6)$ & $16.88(14.2,20.0)$ & $83.12(80.0,85.8)$ & \\
\hline \multicolumn{5}{|l|}{ Age Range: Dentition Status } \\
\hline 1-5: Deciduous Dentition & $30.65(28.6,32.8)$ & $14.32(11.6,17.6)$ & $85.68(82.4,88.4)$ & \multirow[t]{3}{*}{$<0.001$} \\
\hline 6-12: Transitional Dentition & $44.22(41.9,46.6)$ & $32.38(29.1,35.8)$ & $67.62(64.2,70.9)$ & \\
\hline 13-17: Permanent Dentition & $25.12(23.1,27.2)$ & $24.67(20.8,29.0)$ & $75.32(71.0,79.2)$ & \\
\hline \multicolumn{5}{|l|}{ Sex } \\
\hline Male & $51.6(49.3,54.0)$ & $23.98(21.2,27.0)$ & $76.02(73.0,78.8)$ & \multirow[t]{2}{*}{0.361} \\
\hline Female & $48.4(46.0,50.7)$ & $25.90(23.1,29.0)$ & $74.10(71.0,76.9)$ & \\
\hline \multicolumn{5}{|l|}{ Race } \\
\hline White & $58.75(56.4,61.1)$ & $23.93(21.4,26.6)$ & $76.07(73.4,78.6)$ & \multirow[t]{3}{*}{0.275} \\
\hline Black & $3.81(3.0,4.8)$ & $20.78(13.2,31.2)$ & $79.22(68.8,86.9)$ & \\
\hline Other & $37.43(35.1,39.8)$ & $26.87(23.4,30.6)$ & $73.13(69.4,76.5)$ & \\
\hline \multicolumn{5}{|l|}{ Federal Poverty Level (FPL) } \\
\hline$<=100 \% \mathrm{FPL}$ & $35.47(32.3,37.7)$ & $29.11(25.8,32.7)$ & $70.89(67.3,74.2)$ & \multirow[t]{5}{*}{$<0.001$} \\
\hline$>100-150 \% \mathrm{FPL}$ & $16.27(14.6,18.1)$ & $32.30(26.9,38.2)$ & $67.71(61.8,73.1)$ & \\
\hline$>150-200 \% \mathrm{FPL}$ & $12.26(10.7,14.0)$ & $28.91(22.8,36.0)$ & $71.09(64.0,77.2)$ & \\
\hline$>200-400 \% \mathrm{FPL}$ & $21.82(19.9,24.0)$ & $19.71(15.7,24.4)$ & $80.28(75.6,84.3)$ & \\
\hline$>400 \% \mathrm{FPL}$ & $14.17(12.7,15.7)$ & $10.44(8.0,13.5)$ & $89.56(86.5,92.0)$ & \\
\hline \multicolumn{5}{|l|}{ Parent/Guardian Education Status } \\
\hline Not High School Graduate & $50.54(48.2,52.9)$ & $30.29(27.1,33.7)$ & $69.71(66.3,72.9)$ & \multirow[t]{3}{*}{$<0.001$} \\
\hline High School Graduate & $23.36(21.5,25.4)$ & $19.58(27.1,33.7)$ & $80.41(76.6,83.7)$ & \\
\hline Education Beyond High School & $26.09(24.2,28.1)$ & $19.26(16.3,23.4)$ & $80.74(77.3,83.8)$ & \\
\hline \multicolumn{5}{|l|}{ Neighborhood Maintenance } \\
\hline No Dilapidated Housing & $82.23(80.4,83.9)$ & $23.78(21.6,26.1)$ & $76.22(73.9,78.4)$ & \multirow[t]{2}{*}{0.018} \\
\hline Has Dilapidated Housing & $17.77(16.1,19.6)$ & $30.14(25.4,35.4)$ & $69.86(64.3,74.6)$ & \\
\hline \multicolumn{5}{|l|}{ Health Insurance } \\
\hline No Insurance & $9.87(8.5,11.4)$ & $27.43(21.0,34.9)$ & $72.57(65.1,79.0)$ & \multirow[t]{2}{*}{0.044} \\
\hline Insurance & $9.01(88.6,91.5)$ & $24.63(22.5,26.9)$ & $75.68(73.1,77.5)$ & \\
\hline \multicolumn{5}{|l|}{ Past Year Dental Visit } \\
\hline No Dental Visit & $24.15(22.2,26.2)$ & $10.40(8.0,13.4)$ & $89.60(85.7,92.0)$ & \multirow[t]{2}{*}{$<.0001$} \\
\hline Had Dental Visit & $75.85(73.8,77.8)$ & $29.53(27.1,32.1)$ & $70.47(67.9,72.9)$ & \\
\hline \multicolumn{5}{|l|}{ Household Structure } \\
\hline 2 Biological or Adoptive Parents & $66.51(64.3,68.7)$ & $23.49(21.1,26.0)$ & $76.51(74.0,78.9)$ & \multirow[t]{4}{*}{0.159} \\
\hline 2 Parents and 1 is a Stepparent & $9.51(8.2,11.0)$ & $29.38(22.6,37.3)$ & $70.62(62.7,77.4)$ & \\
\hline Single Mother & $20.44(18.7,22.3)$ & $28.46(24.1,33.2)$ & $71.54(66.8,75.9)$ & \\
\hline Other & $3.55(2.7,4.7)$ & $19.10(9.4,35.0)$ & $80.91(65.0,90.6)$ & \\
\hline
\end{tabular}


Table 2 Unadjusted associations between dental caries and characteristics of Hispanic children residing in the United States (unweighted $n=9143$ ) (Continued)

\begin{tabular}{|c|c|c|c|c|}
\hline & \multirow{2}{*}{$\begin{array}{l}\text { Total Sample } \\
\text { (Column \%) }\end{array}$} & \multicolumn{2}{|c|}{ Dental Caries in Past Year (Row \%) } & \multirow[t]{2}{*}{$p$-value } \\
\hline & & Had Dental Caries & No Dental Caries & \\
\hline \multicolumn{5}{|c|}{ Number Children in Household $(\mathrm{HH})$} \\
\hline 1 Child in $\mathrm{HH}$ & $19.50(17.9,21.2)$ & $21.25(17.5,25.6)$ & $78.75(74.2,82.5)$ & \multirow[t]{2}{*}{0.067} \\
\hline$>1$ Child in $\mathrm{HH}$ & $80.50(78.8,82.1)$ & $25.79(23.5,28.2)$ & $74.21(71.8,76.5)$ & \\
\hline \multicolumn{5}{|l|}{ Neighbors Help Each Other } \\
\hline Strongly Agree & $34.29(32.1,36.5)$ & $24.30(21.0,27.9)$ & $75.70(72.1,79.0)$ & \multirow[t]{3}{*}{0.3482} \\
\hline Somewhat Agree & $44.67(42.4,47.0)$ & $23.98(21.1,27.2)$ & $76.02(72.8,78.9)$ & \\
\hline Disagree & $21.03(19.2,23.0)$ & $27.87(23.4,32.9)$ & $72.13(67.1,76.6)$ & \\
\hline \multicolumn{5}{|c|}{ Child with Special Healthcare Needs (CSHN) } \\
\hline Not CSHN & $83.35(81.6,85.0)$ & $24.16(22.0,26.5)$ & $75.84(73.5,78.0)$ & \multirow[t]{2}{*}{0.111} \\
\hline $\mathrm{CSHN}$ & $16.65(15.0,18.4)$ & $28.65(23.7,34.2)$ & $71.35(65.8,76.2)$ & \\
\hline \multicolumn{5}{|c|}{ Parent/Guardians' Health Status } \\
\hline All Excellent or Good & $74.64(72.6,76.6)$ & $21.26(19.1,23.6)$ & $78.74(76.2,81.9)$ & \multirow[t]{2}{*}{$<0.001$} \\
\hline$\geq 1$ Fair or Poor & $25.36(23.4,27.4)$ & $35.65(31.2,40.3)$ & $64.35(59.7,68.8)$ & \\
\hline
\end{tabular}

Data are from the 2010-2011 National Survey of Children's Health (NSHS) and include a sample of Hispanic children ages 1 to 17 residing in the United States. All estimates account for NSCH weighting and complex sampling design and thus are nationally representative. Percentages and $95 \%$ confidence intervals given. Unadjusted differences in proportion with dental caries were tested with chi-square tests; $p$-values given

analyses $(p>0.05$ for all). Household poverty level was associated with dental caries in unadjusted analyses $(p<$ 0.001 ). In adjusted analyses, children residing in households with incomes above $400 \%$ of the federal poverty level were significantly less likely to experience dental caries than those residing at or below the federal poverty level $(p=0.001)$.

Lower educational levels of the parents/guardians were significantly associated with an increased likelihood of dental caries in unadjusted analyses $(\mathrm{p}<0.001)$, but these differences were not significant in adjusted analyses $(p>$ 0.05 for all). Conversely, a lack of neighborhood maintenance was significantly associated with an increased likelihood of dental caries in both unadjusted $(p=0.018)$ and adjusted analyses $(p=0.014)$. Health insurance was not significantly associated with dental caries in either unadjusted $(p=0.440)$ or adjusted $(p=0.343)$ analyses, although past-year dental visits were associated with an increased likelihood of dental caries in both unadjusted and adjusted analyses ( $p<0.001$ for both).

Household structure was not significantly associated with dental caries in unadjusted analyses $(p=0.159)$, but in adjusted analyses children residing in a household with a single mother were significantly more likely to experience dental caries as compared to those living in a household with two biological or adoptive parents ( $p=$ 0.031). Neither the number of children in the household nor the helpfulness of neighbors was significantly associated with dental caries in the unadjusted or adjusted analyses $(p>0.05$ for all). Based on unadjusted and adjusted analyses, children with special healthcare needs were not significantly more likely to experience dental caries $(p=0.111$ and $p=0.084$, respectively). However, fair or poor health status of parents/guardians was significantly associated with an increased likelihood of dental caries in both unadjusted and adjusted analyses $(p<$ 0.001 for both).

\section{Discussion}

The results of our investigation indicate that household acculturation is a significant predictor for dental caries among Hispanic children in the US. These findings concur with existing evidence which projects a general positive and protective effect of acculturation among immigrant and ethnic minorities on oral health-related quality of life $[11,28]$. Our investigation adds to the literature by confirming these findings in a nationally representative sample of Hispanic children from all dentition categories. We also demonstrate the presence of a dose-response relationship between the extent of a Hispanic household's acculturation to the US and pediatric oral health.

The impact of acculturation on oral health must be considered within the context of other health outcomes. The findings of research examining the association between physical health outcomes and acculturation in immigrant and minority populations are inconsistent. Depending on the migration pattern, these vulnerable populations are exposed to a variety of challenges and changes, including language barriers, sociocultural norms, nutrition, and overall lifestyle options and choices. The evidence is mixed regarding the risks and/ 
Table 3 Results of a logistic regression model examining the adjusted association between dental caries and acculturation in Hispanic children residing in the United States, adjusting for demographic and social determinants of pediatric oral health (unweighted $n=9143$ )

\begin{tabular}{|c|c|c|c|}
\hline & Odds Ratio (95\% Cl) & $p$-value & Average Predicted Probability (95\% Cl) \\
\hline \multicolumn{4}{|l|}{ Household Acculturation } \\
\hline Low Acculturation & (Ref) & & $29.5 \%(26.2,32.9 \%)$ \\
\hline Moderate Acculturation & $0.693(0.47,1.01)$ & 0.057 & $23.2 \%(18.3,28.1 \%)$ \\
\hline High Acculturation & $0.499(0.35,0.70)$ & 0.000 & $18.3 \%(14.9,21.7 \%)$ \\
\hline \multicolumn{4}{|l|}{ Age Range: Dentition Status } \\
\hline 1-5: Deciduous Dentition & (Ref) & & $16.6 \%(13.2,19.9 \%)$ \\
\hline 6-12: Transitional Dentition & $2.39(1.76,3.23)$ & 0.000 & $30.4 \%(27.4,33.3 \%)$ \\
\hline 13-17: Permanent Dentition & $1.65(1.154,2.37)$ & 0.006 & $23.9 \%(20.1,27.8 \%)$ \\
\hline \multicolumn{4}{|l|}{ Sex } \\
\hline Male & (Ref) & & $23.5 \%(20.9,26.1 \%)$ \\
\hline Female & $1.19(0.95,1.50)$ & 0.126 & $26.4 \%(23.7,29.1 \%)$ \\
\hline \multicolumn{4}{|l|}{ Race } \\
\hline White & (Ref) & & $24.8 \%(22.4,27.3 \%)$ \\
\hline Black & $0.93(0.49,1.76)$ & 0.819 & $23.6 \%(13.7,33.5 \%)$ \\
\hline Other & $1.021(0.87, .80)$ & 0.868 & $25.2 \%(22.0,28.3 \%)$ \\
\hline \multicolumn{4}{|l|}{ Federal Poverty Level (FPL) } \\
\hline$<=100 \% \mathrm{FPL}$ & (Ref) & & $25.8 \%(22.4,29.1 \%)$ \\
\hline$>100-150 \% \mathrm{FPL}$ & $1.29(0.92,1.82)$ & 0.146 & $30.3 \%(25.0,35.7 \%)$ \\
\hline$>150-200 \% \mathrm{FPL}$ & $1.19(0.81,1.76)$ & 0.371 & $28.9 \%(23.0,34.8 \%)$ \\
\hline$>200-400 \% \mathrm{FPL}$ & $0.82(.560,1.21)$ & 0.317 & $22.5 \%(17.8,27.3 \%)$ \\
\hline$>400 \% \mathrm{FPL}$ & $0.45(0.29,0.71)$ & 0.001 & $14.3 \%(10.1,18.5 \%)$ \\
\hline \multicolumn{4}{|l|}{ Parent/Guardian Education Status } \\
\hline Not High School Graduate & (Ref) & & $25.7 \%(22.6,28.8 \%)$ \\
\hline High School Graduate & $0.85(0.61,1.18)$ & 0.333 & $23.1 \%(19.2,27.0 \%)$ \\
\hline Education Beyond High School & $0.93(0.66,1.31)$ & 0.678 & $24.5 \%(20.4,28.6 \%)$ \\
\hline \multicolumn{4}{|l|}{ Neighborhood Maintenance } \\
\hline No Dilapidated Housing & (Ref) & & $23.8 \%(21.7,25.9 \%)$ \\
\hline Has Dilapidated Housing & $1.42(1.08,1.90)$ & 0.014 & $29.9 \%(25.3,34.5 \%)$ \\
\hline \multicolumn{4}{|l|}{ Health Insurance } \\
\hline No Insurance & (Ref) & & $28.1 \%(20.8,35.4 \%)$ \\
\hline Insurance & $0.810(0.52,1.25)$ & 0.343 & $24.6 \%(22.6,26.5 \%)$ \\
\hline \multicolumn{4}{|l|}{ Past Year Dental Visit } \\
\hline No Dental Visit & (Ref) & & $11.0 \%(8.4,13.7 \%)$ \\
\hline Had Dental Visit & $3.64(2.65,4.98)$ & 0.000 & $29.0 \%(26.6,31.4 \%)$ \\
\hline \multicolumn{4}{|l|}{ Household Structure } \\
\hline 2 Biological or Adoptive Parents & (Ref) & & $23.2 \%(20.9,25.5 \%)$ \\
\hline 2 Parents and 1 is a Stepparent & $1.37(0.91,2.05)$ & 0.133 & $28.4 \%(21.8,35.0 \%)$ \\
\hline Single Mother & $1.37(1.03,1.83)$ & 0.031 & $28.5 \%(24.2,32.8 \%)$ \\
\hline Other & $1.22(0.55,2.71)$ & 0.627 & $26.5 \%(13.0,39.9 \%)$ \\
\hline \multicolumn{4}{|l|}{ Number Children in Household $(\mathrm{HH})$} \\
\hline 1 Child in $\mathrm{HH}$ & (Ref) & & $24.0 \%(19.8,28.1 \%)$ \\
\hline$>1$ Child in $\mathrm{HH}$ & $1.07(0.80,1.44)$ & 0.630 & $25.1 \%(23.0,27.3 \%)$ \\
\hline
\end{tabular}


Table 3 Results of a logistic regression model examining the adjusted association between dental caries and acculturation in Hispanic children residing in the United States, adjusting for demographic and social determinants of pediatric oral health (unweighted $n=9143$ ) (Continued)

\begin{tabular}{|c|c|c|c|}
\hline & Odds Ratio $(95 \% \mathrm{Cl})$ & $p$-value & Average Predicted Probability (95\% Cl) \\
\hline \multicolumn{4}{|c|}{ Neighbors Help Each Other } \\
\hline Strongly Agree & (Ref) & & $25.9 \%(22.6,29.2 \%)$ \\
\hline Somewhat Agree & $0.93(0.71,1.21)$ & 0.578 & $24.7 \%(21.8,27.6 \%)$ \\
\hline Disagree & $0.89(0.64,1.22)$ & 0.450 & $23.9 \%(20.1,27.3 \%)$ \\
\hline \multicolumn{4}{|c|}{ Child with Special Healthcare Needs (CSHN) } \\
\hline Not CSHN & (Ref) & & $24.1 \%(22.1,26.2 \%)$ \\
\hline CSHN & $1.32(0.96,1.9)$ & 0.084 & $28.7 \%(23.8,33.7 \%)$ \\
\hline \multicolumn{4}{|c|}{ Parent/Guardian Health Status } \\
\hline All Excellent or Good & (Ref) & & $22.5 \%(20.3,24.7 \%)$ \\
\hline$\geq 1$ Fair or Poor & $1.65(1.26,2.16)$ & 0.000 & $31.1 \%(27.0,35.3 \%)$ \\
\hline
\end{tabular}

Data are from the 2010-2011 National Survey of Children's Health (NSHS) and include a sample of Hispanic children ages 1 to 17 residing in the United States. All estimates account for NSCH weighting and complex sampling design and thus are nationally representative. The outcome of interest was oral health as measured by the presence of dental caries, and household acculturation was the primary explanatory variable. The average predicted probabilities represent the adjusted probability of having dental caries at each category of the predictor variables. They are based on the average predicted probability of having dental caries conditional on all observations having a given value of the predictor variable, and they are expressed as percentages

or protective impacts of acculturation on various health issues and outcomes in immigrant and minority populations, perhaps because acculturation is not dichotomous, but rather reflects a continuum with various stages of adoption [9, 10, 29, 34, 35]. Further, persons will experience varied health consequences depending on the observed behavior changes and the health outcome being studied. For example, some evidence suggests that unrestricted acceptance of westernized norms, particularly diet, leads to an increased risk for chronic health conditions such as cardiovascular disease and diabetes [11]. Contrastingly, evidence also demonstrates a positive correlation between acculturation and utilization of preventive healthcare services, including but not limited to preventive dental health services [36-39]. However, the utilization of healthcare services does not necessarily equate to improvement in health. Literature on Hispanic populations, in particular, suggests a somewhat protective and paradoxical health benefit when Hispanics are resistant to acculturation. Essentially, the concept of the

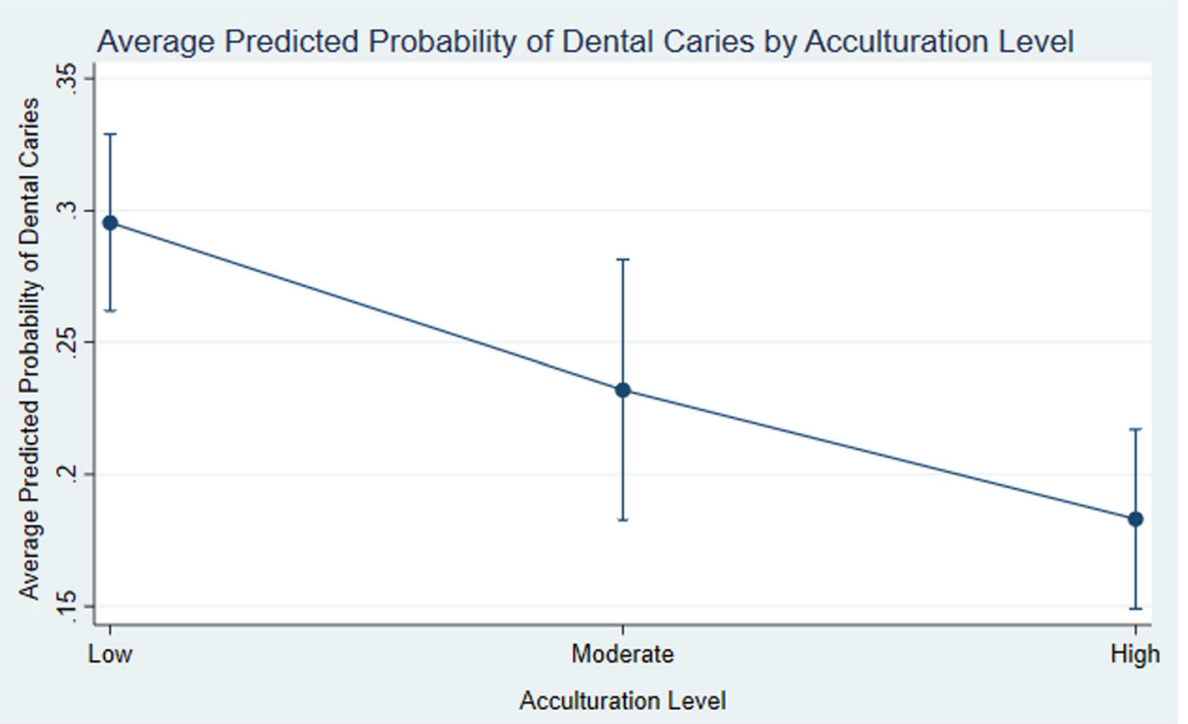

Fig. 1 Average predicted probabilities of dental caries by acculturation level in Hispanic children residing in the United States, based on the results of a multivariable logistic regression model that adjusts for demographic and social determinants of pediatric oral health. Detailed model results are available in Table 3 
Hispanic Paradox claims that certain sociocentric protective forces operate, intrinsically, within the Hispanic community, including knowledge, attitudes, beliefs, and behaviors pertaining to health and healthcare [29, 40]. The results from our study contests and cautions against using the term "Hispanic Paradox" universally, as it does not appear to apply in the context of oral health.

Our results also highlight the potential role of broader family and community-level factors in affecting oral health, and further investigation in this area is warranted. A major gap that continues to be understudied is the qualitative, social determinants that influence oral health. Parental education, oral health literacy, access to care, material deprivation, poor dietary and hygiene habits, decreased social support, and employment issues are all identified as key areas within social determinants of pediatric oral health [32]. Furthermore, social network theories suggest that health beliefs, behaviors, and values are largely influenced by the context in which people live [41]. For example, the influence of social support systems, communal connectivity, and neighborhood environments are critical factors in predicting the extent of impact sociocultural forces can have on quality of life. In Hispanic communities, studies suggest a protective effect of specific ethnocentric values, namely reciprocity and social relationships, which appears to dissipate as time residing in US increases [40]. Our results support the significant impact of certain social determinants beyond acculturation, specifically household income, household structure, parental/guardian health status, and dilapidated housing environments, on dental caries among Hispanic children in the US. One possible explanation is that proximate connection with certain sociocentric values and identity play a vital role in preserving health. Therefore, future efforts should focus on the extent to which social determinants of health, particularly family structure and extended social networks, influence oral health-related quality of life among Hispanic households in the US.

Cultural competency for healthcare professionals is paramount when striving to provide quality care to a diverse array of patients, particularly immigrant and minority populations. Based on the results from our investigation, less-acculturated Hispanic households are at the highest risk for oral diseases. Clinical and public health professionals should prioritize oral healthcare interventions on less-acculturated Hispanic households. A variety of obstacles to improving health and acquiring healthcare may already exist for Hispanics who are lessacculturated in the US, such as linguistic and financial barriers, ethnocentric health belief systems, navigating national health reform and insurance policies, and more. For immigrant and minority populations, conducting successful preventive interventions often requires a culturally sensitive interprofessional-based and/or community-based approach [29]. Health literacy must also be considered when developing interventions for Hispanic populations, as prior studies indicate that lower levels of acculturation may be associated with lower levels of health literacy [42, 43]. Future studies are needed to explore how health literacy may moderate or mediate the relationship between household acculturation levels and pediatric oral health.

Communication, or lack thereof, another prominent obstacle in the healthcare industry. Evidence suggests that integrating the use of professional interpretation services, incorporating culturally sensitive motivational patient interviewing techniques, employing multilingual staff, utilizing multilingual forms, and regularly collecting patient feedback can help in improving total quality management in medical and dental offices [29]. Moreover, regular interprofessional training and continuing education exercises in cultural competency and literacyoriented communication can help improve healthcare professionals' knowledge, awareness, and attitudes towards cultural sensitivities and variations in health literacy across diverse populations. Broader public healthbased interventions should include key stakeholders in the community, such as involvement of community health workers who are more acculturated, but also sensitive to the unique needs of the targeted patient populations [29]. Further effort is needed on building more effective health policies and interventions that improve the cultural competence and communication of healthcare practitioners in the US.

Over the past decade, numerous policies have been implemented which strive to ensure that the healthcare needs of persons at varying levels of health literacy are met $[44,45]$. In an increasingly diverse national population, there is a need for similar policies that will enable persons at all acculturation levels to receive timely, high quality healthcare. Such policies could help facilitate regular cultural competency-focused training and continuing education for practicing dental health professionals in an effort to reduce existing communication and knowledge gaps. Furthermore, at the academic level, accrediting bodies could make sure that schools teaching future generations of the dental health workforce integrate diversity education and cultural competency as part of their curriculum. At the community level, public health professionals should incorporate acculturation as an integral component of their program implementation strategies [46], and when such programs are focused on dental health in the Hispanic pediatric population these professionals should consider focusing resources on children who reside in less acculturated households given their higher risk of oral health issues. Social media health campaigns appropriately tailored to persons at different levels of acculturation should also be 
considered in today's digital age; these campaigns could stress the importance of dental self-care and regular dental healthcare.

Payers, particularly state Medicaid plans, may also play a role in facilitating culturally competent care. Approximately $56 \%$ of Hispanic children are enrolled in Medicaid [47], and all Medicaid plans are required to cover dental care for pediatric enrollees [48]. It is likely that the Hispanic children enrolled in Medicaid reside in households with a diverse range of acculturation and health literacy levels, as over half of US-born Hispanic children have at least one parent born outside of the US [49]. With the Centers for Medicare and Medicaid Services asking states to consider outreaching to families of children on Medicaid in order to provide education on the importance of oral health care for children [50], Medicaid plans may be in a unique position to develop and implement oral health-related interventions that accommodate the needs of a large volume of Hispanic children residing in households with varying acculturation and health literacy levels.

Acculturation is an extraordinarily complex, multidimensional, and multidirectional process that shifts the health beliefs, behaviors, and lifestyles of people transitioning between their home and host countries [29]. Given this complexity, there is no single universally accepted parameter to measure the extent of acculturation. Consistent with much of the past research examining acculturation and oral health [13, 15, 16, 19, 21, 23, 35], the current study used a proxy measure of acculturation based on language and nativity. There is a need for future studies with nationally representative samples of children which use validated instruments when examining the association between pediatric oral health and acculturation.

$\mathrm{NSCH}$ data provided an opportunity to examine oral health and acculturation in a sizable sample of nationally representative Hispanic children across a broad range of ages. However, this data source also has limitations. Its cross-sectional nature disallows us from making causal statements or examining changes in oral health as the acculturation process occurs, and the question used to measure oral health focused on "toothache, decayed teeth, or unfilled cavities" rather than the full spectrum of potential pediatric oral health issues. Further, oral health was measured based on parental report rather than clinical examination, so there is the possibility that some children with dental caries were not identified as such [51]. Nonetheless, there is a positive correlation between parental report of pediatric oral health and findings from clinical examinations, and valid and reliable oral health information can be obtained from parents regarding their children when data are collected via questionnaire [51].
Missing data was a challenge of the NSCH data; sociodemographic variables were not available for all children, and children with missing data were excluded from analysis. No data were available on oral health-related behaviors, so such behaviors could not be examined in the current study. We were also unable to identify whether children currently or formerly resided in areas without community water fluoridation, and the presence or absence of such fluoridation may have affected the outcome of interest. Additionally, the NSCH survey asks about children's health insurance coverage, but it does not ask whether insurance coverage includes dental benefits. As having medical coverage is associated with an increase in dental visits even without dental benefit coverage [52], we adjusted for the presence of health insurance in our analyses. However, we were unable to adjust for the presence or absence of dental insurance benefits.

Finally, the NSCH data source did not contain sufficient information to explore how the relationship between acculturation and oral health may vary within the US's ethnically diverse Hispanic population. In the US, Hispanics of Mexican, Puerto Rican, Salvadorian, Cuban, Dominican, Guatemalan, and Columbian origins each represent subpopulations of greater than 1 million persons, and numerous smaller Hispanic subgroups are also present [1]. Previous research indicates that oral health status varies by Hispanic subpopulation [53]. Further, each subpopulation has a distinct cultural heritage, and thus acculturation processes may vary by subpopulation. The NSCH did not identify the children's countries or cultures of origin [54], so the exploration of potentially differing relationship between oral health and acculturation within the different subpopulations of Hispanic persons in the US represents an opportunity for future research that builds on the findings of the current study. That said, while Hispanic immigrants come to the US from a variety of countries, the confluence of a common language, human capital disadvantages, and circumstances within the US result in a "distinctive profile for Hispanics as a whole" [55]. There is a great need for public health research on the Hispanic pediatric population, as Hispanic children represent a growing proportion of the US population [1] and a number of health and healthcare disparities are observed when comparing Hispanic and non-Hispanic children [3, 56-58].

Despite the limitations, this study has substantial strengths and it adds to the literature in important ways. The NSCH provides rich data on multiple, intersecting aspects of children's lives, including the child's family and social context. Consequently, we were able to account for these factors when examining the relationship between oral health and acculturation in Hispanic children. Further, our study uses a large, nationally 
representative sample of Hispanic children of across a broad age range, comprising all dentition stages (primary, mixed, and permanent).

\section{Conclusions}

A considerable body of past research suggests that acculturation typically improves oral health outcomes of Hispanic adults in the US [11], but the association between acculturation and oral health in Hispanic children was previously not well-studied. Given the large number of Hispanic children in the US [1], the oral health disparities experienced by these children [8], and the effects of oral health on quality of life and other aspects of children's health [6], the current study fills an important gap in the pediatric oral health research literature. Based on a nationally representative sample of children, we observed a dose-response relationship between household acculturation and the oral health of Hispanic children in the US. As the level of acculturation increased, Hispanic children's oral health increased. Thus, children residing in less acculturated households were at the greatest risk of dental caries. Our findings suggest that public health and community-based interventions intended to reduce oral health disparities in Hispanic children are likely to be most impactful if the acculturation levels of the children's households are considered during program development.

\section{Abbreviations \\ CSHN: Child with special healthcare needs; FPL: Federal poverty level; HH: Household; NSCH: National Survey of Children's Health; US: United States of America \\ Acknowledgements \\ The authors would like to acknowledge Won Seok Choi, PhD, who generously shared his time in support of the authors of this paper.}

\section{Authors' contributions}

FAK conceptualized the study and identified the data source. FAK and ELS developed the proxy acculturation variable. BBV reviewed the literature. ELS analyzed the data. ELS, FAK, BBV and ADL interpreted the data analysis results. ELS and FAK drafted the manuscript. ELS, FAK, BBV and ADL revised the manuscript for important intellectual content. ELS, FAK, BBV and ADL approved the final version of the manuscript. All authors take responsibility for the content of this study. The opinions expressed in this manuscript are those of the authors and do not necessarily represent the views of the organizations with which they are affiliated.

\section{Funding}

No funding was received for the current study.

\section{Availability of data and materials}

The 2011-2012 National Survey of Children's Health dataset used is this study is publicly available on the Centers for Disease Control and Prevention website, at https://www.cdc.gov/nchs/slaits/nsch.htm.

\section{Ethics approval and consent to participate}

This project was reviewed and approved as expedited category research by the Institutional Review Board of the Office of Research Compliance at the University of North Texas Health Science Center.

\section{Consent for publication}

Not applicable.

\section{Competing interests}

The authors declare that they have no competing interests.

\section{Author details}

${ }^{1}$ Caruth School of Dental Hygiene, Texas A\&M University College of Dentistry, 3302 Gaston Avenue, Suite 136, Dallas, TX 75246, USA. ${ }^{2}$ Department of Health Behavior and Health Systems; School of Public Health, University of North Texas Health Science Center, 3500 Camp Bowie Blvd, Fort Worth, TX 76107, USA. ${ }^{3}$ Department of Advanced Health Analytics and Solutions; Magellan Health, Inc., 4800 N. Scottsdale Rd. \#4400, Scottsdale, AZ 85251, USA. ${ }^{4}$ SaferCare Texas; University of North Texas Health Science Center, 3500 Camp Bowie Blvd, Fort Worth, TX 76107, USA.

Received: 25 July 2019 Accepted: 6 December 2019

Published online: 28 January 2020

\section{References}

1. Pew Research Center: FACTANK. How the U.S. Hispanic population is changing. https://www.pewresearch.org/fact-tank/2017/09/18/how-the-u-shispanic-population-is-changing/. Accessed 14 Nov 2019.

2. United States Census Bureau: American FactFinder. https://factfinder.census. gov/faces/nav/jsf/pages/index.xhtml. Accessed 14 Nov 2019.

3. Fleming E, Afful J: NCHS Data Brief No. 307: Prevalence of Total and Untreated Dental Caries Among Youth: United States, 2015-2016. Centers for Disease Control and Prevention, National Center for Health Statistics; 2018. https://www.cdc.gov/nchs/products/databriefs/db307.htm. Accessed 14 Nov 2019.

4. World Health Organization. Oral health: Key facts. https://www.who.int/ news-room/fact-sheets/detail/oral-health. Accessed 14 Nov 2019.

5. Sheiham A. Oral health, general health and quality of life. Bull World Health Organ. 2005;83(9):644-5.

6. Mayo Clinic. Oral health: A window to your overall health. https://www. mayoclinic.org/healthy-lifestyle/adult-health/in-depth/dental/art-20047475. Accessed 14 Nov 2019.

7. Kaur P, Singh S, Mathur A, Makkar DK, Aggarwal VP, Batra M, Sharma A, Goyal N. Impact of dental disorders and its influence on self esteem levels among adolescents. J Clin Diagn Res. 2017;11(4):ZC05-8.

8. Centers for Disease Control and Prevention. Oral health: preventing cavities, gum disease, tooth loss, and oral cancers: at a glance 2011. 2011. https:// stacks.cdc.gov/view/cdc/11862. Accessed 14 Nov 2019.

9. Berry JW. Immigration, acculturation, and adaption. Appl Psychol Int Rev. 1997:46(1):5-68

10. Schwartz SJ, Zamboanga BL. Testing Berry's model of acculturation: a confirmatory latent class approach. Cultur Divers Ethnic Minor Psychol. 2008; 14(4):275-85.

11. Dahlan R, Badri P, Saltaji H, Amin M. Impact of acculturation on oral health among immigrants and ethnic minorities: a systematic review. PLoS One. 2019:14(2):e0212891.

12. Riley JL 3rd, Gibson E, Zsembik BA, Duncan RP, Gilbert GH, Heft MW. Acculturation and orofacial pain among Hispanic adults. J Pain. 2008:9(8):750-8.

13. Spolsky WW, Marcus M, Coulter ID, Der-Martirosian C, Atchison KA. An empirical test of the validity of the Oral Health status index (OHSI) on a minority population. J Dent Res. 2000;79(12):1983-8.

14. Ismail Al, Szpunar SM. Oral health status of Mexican-Americans with low and high acculturation status: findings from southwestern HHANES, 198284. J Public Health Dent. 1990;50(1):24-31.

15. Cruz GD, Chen Y, Salazar CR, Le Geros RZ. The association of immigration and acculturation attributes with oral health among immigrants in New York City. Am J Public Health. 2009:99(Suppl 2):S474-80.

16. Luo H, Hybels CF, Wu B. Acculturation, depression and oral health of immigrants in the USA. Int Dent J. 2018;68(4):245-52.

17. Garcia D, Tarima S, Glasman L, Cassidy LD, Meurer J, Okunseri C. Latino acculturation and periodontitis status among Mexican-origin adults in the United States: NHANES 2009-2012. Fam Community Health. 2017;40(2):112-20.

18. Finlayson TL, Lemus H, Becerra K, Kaste LM, Beaver SM, Salazar CR, Singer $\mathrm{RH}$, Youngblood ME Jr. Unfair treatment and periodontitis among adults in the Hispanic community Health study/study of Latinos (HCHS/SOL). J Racial Ethn Health Disparities. 2018;5(5):1093-106.

19. Swoboda J, Kiyak HA, Persson RE, Persson GR, Yamaguchi DK, MacEntee MI, Wyatt CC. Predictors of oral health quality of life in older adults. Spec Care Dentist. 2006;26(4):137-44. 
20. Silveira ML, Dye BA, lafolla TJ, Adesanya MR, Boroumand S, Youngblood ME, Salazar CR, Finlayson TL, Khambaty T, Beaver SM, et al. Cultural factors and oral health-related quality of life among dentate adults: Hispanic community Health study/study of Latinos. Ethn Health. 2018:1-16.

21. Nurko C, Aponte-Merced L, Bradley EL, Fox L. Dental caries prevalence and dental health care of Mexican-American workers' children. ASDC J Dent Child. 1998;65(1):65-72.

22. Watson MR, Horowitz AM, Garcia I, Canto MT. Caries conditions among 2-5year-old immigrant Latino children related to parents' oral health knowledge, opinions and practices. Community Dent Oral Epidemiol. 1999; 27(1):8-15.

23. Quandt SA, Clark HM, Rao P, Arcury TA. Oral health of children and adults in Latino migrant and seasonal farmworker families. J Immigr Minor Health. 2007:9(3):229-35.

24. Edelstein $\mathrm{BL}$, Chinn $\mathrm{CH}$. Update on disparities in oral health and access to dental care for America's children. Acad Pediatr. 2009;9(6):415-9.

25. Child and Adolescent Health Measurement Initiative: Fast Facts: 2011/12 National Survey of Children's Health. Data Resource Center, supported by Cooperative Agreement 1-U59-MC06980-01 from the U.S. Department of Health and Human Services, Health Resources and Services Administration (HRSA), Maternal and Child Health Bureau (MCHB). https://www. childhealthdata.org/learn-about-the-nsch/archive-prior-year-datadocuments-and-resources. Accessed 14 Nov 2019.

26. American Academy of Pediatric Dentistry. Guideline on caries-risk assessment and management for infants, children, and adolescents. https://www.aapd.org/research/oral-health-policies\%2D\%2 Drecommendations/caries-risk-assessment-and-management-for-infantschildren-and-adolescents/. Accessed 14 Nov 2019.

27. Portes A, Rumbaut RG. Legacies: the story of the immigrant second generation. 1st ed. Oakland: University of California Press; 2001.

28. Gao XL, McGrath C. A review on the oral health impacts of acculturation. J Immigr Minor Health. 2011;13(2):202-13.

29. Tiwari T, Albino J. Acculturation and pediatric minority oral health interventions. Dent Clin N Am. 2017;61(3):549-63.

30. Cuellar I, Nyberg B, Maldonado RE. Ethnic identity and acculturation in a young adult Mexican-origin population. J Community Psychol. 1997;25(6): 535-49.

31. Wallace PM, Pomery EA, Latimer AE, Martinez $J$, Salovey P. A review of ccculturation measures and their utility in studies promoting Latino health. Hisp J Behav Sci. 2010;32(1):37-54.

32. da Fonseca MA, Avenetti D. Social determinants of pediatric oral health. Dent Clin N Am. 2017;61(3):519-32.

33. UCLA Institute for Digital Research \& education. Logistic regression: Stata data analysis examples. https://stats.idre.ucla.edu/stata/dae/logisticregression/. Accessed 14 November 2019.

34. DuBard CA, Gizlice Z. Language spoken and differences in health status, access to care, and receipt of preventive services among US Hispanics. Am J Public Health. 2008;98(11):2021-8.

35. Ebin VJ, Sneed CD, Morisky DE, Rotheram-Borus MJ, Magnusson AM, Malotte CK. Acculturation and interrelationships between problem and health-promoting behaviors among Latino adolescents. J Adolesc Health. 2001;28(1):62-72.

36. Akresh IR. Health service utilization among immigrants to the United States. Popul Res Policy Rev. 2009;28:795-815.

37. Finlayson TL, Asgari P, Dougherty E, Tadese BK, Stamm N, Nunez-Alvarez A. Child, caregiver, and family factors associated with child dental utilization among Mexican migrant families in California. Community Dent Health. 2018;35(2):89-94.

38. Noyce M, Szabo A, Pajewski NM, Jackson S, Bradley TG, Okunseri C. Primary language spoken at home and children's dental service utilization in the United States. J Public Health Dent. 2009;69(4):276-83.

39. Yu SM, Bellamy HA, Schwalberg RH, Drum MA. Factors associated with use of preventive dental and health services among U.S. adolescents. J Adolesc Health. 2001;29(6):395-405

40. Sanders AE. A Latino advantage in oral health-related quality of life is modified by nativity status. Soc Sci Med. 2010;71(1):205-11.

41. Maupome G, McConnell WR, Perry BL, Marino R, Wright ER. Psychological and behavioral acculturation in a social network of Mexican Americans in the United States and use of dental services. Community Dent Oral Epidemiol. 2016;44(6):540-8.
42. Ciampa PJ, White RO, Perrin EM, Yin HS, Sanders LM, Gayle EA, Rothman RL. The association of acculturation and health literacy, numeracy and healthrelated skills in Spanish-speaking caregivers of young children. J Immigr Minor Health. 2013;15(3):492-8.

43. De Alba A, Britigan DH, Lyden E, Johansson P. Assessing the prevalence and association of acculturation and health literacy levels in Spanish-speaking Hispanic patients at midwestern community health centers in the USA. J Racial Ethn Health Disparities. 2019;6(4):701-6.

44. Koh HK, Berwick DM, Clancy CM, Baur C, Brach C, Harris LM, Zerhusen EG. New federal policy initiatives to boost health literacy can help the nation move beyond the cycle of costly 'crisis care'. Health Aff. 2012;31(2):434-43.

45. Centers for Disease Control and Prevention. Health literacy activities by state. https://www.cdc.gov/healthliteracy/statedata/index.html . Accessed 14 Nov 2019

46. Lara M, Gamboa C, Kahramanian MI, Morales LS, Bautista DE. Acculturation and Latino health in the United States: a review of the literature and its sociopolitical context. Annu Rev Public Health. 2005;26:367-97.

47. Georgetown University Health Policy Institute Center for Children and Families. Medicaid's role for children. https://ccf.georgetown.edu/wpcontent/uploads/2016/06/Medicaid-and-Children-update-Jan-2017-rev.pdf. Accessed 14 Nov 2019.

48. Medicaid.gov. Dental care: dental benefits for children in Medicaid. https://www. medicaid.gov/medicaid/benefits/dental/index.html. Accessed 14 Nov 2019

49. Murphey D, Guzman L, Torres A: America's Hispanic children: gaining ground, looking forward. Child Trends; 2014. https://www.childtrends.org/ publications/americas-hispanic-children-gaining-ground-looking-forward. Accessed 14 Nov 2019.

50. CMS Oral Health Strategy: Improving access to and utilization of oral health services for children in Medicaid and CHIP programs. 2011. https://www. medicaid.gov/medicaid/quality-of-care/downloads/cms-oral-health-strategy. pdf. Accessed 14 Nov 2019.

51. Barbosa TS, Gaviao MB. Oral health-related quality of life in children: part III. Is there agreement between parents in rating their children's oral healthrelated quality of life? A systematic review. Int J Dent Hyg. 2008;6(2):108-13.

52. Manski RJ, Cooper PF. Dental care use: does dental insurance truly make a difference in the US? Community Dent Health. 2007;24(4):205-12.

53. Spolsky WW, Marcus M, Der-Martirosian C, Coulter ID, Maida CA. Oral health status and the epidemiologic paradox within Latino immigrant groups. BMC Oral Health. 2012;12:39.54.

54. Bramlet MD, Blumberg SJ, Zablotsky B, George JM, Ormson AE, Frasier AM, Wang F. Design and operation of the National Survey of Children's Health, 2011-2012. Vital and Health statistics. Natl Center Health Stat. 2017;1(59)1256. https://www.cdc.gov/nchs/data/series/sr_01/sr01_059.pdf.

55. National Research Council. Hispanics and the future of America. Washington, DC: The National Academies Press; 2006.

56. Mehta NK, Lee H, Ylitalo KR. Child health in the United States: recent trends in racial/ethnic disparities. Soc Sci Med. 2013;95:6-15.

57. Calvo R, Hawkins SS. Disparities in quality of healthcare of children from immigrant families in the US. Matern Child Health J. 2015;19(10):2223-32.

58. Flores G, Olson L, Tomany-Korman SC. Racial and ethnic disparities in early childhood health and health care. Pediatrics. 2005;115(2):e183-93.

\section{Publisher's Note}

Springer Nature remains neutral with regard to jurisdictional claims in published maps and institutional affiliations.

\section{Ready to submit your research? Choose BMC and benefit from:}

- fast, convenient online submission

- thorough peer review by experienced researchers in your field

- rapid publication on acceptance

- support for research data, including large and complex data types

- gold Open Access which fosters wider collaboration and increased citations

- maximum visibility for your research: over $100 \mathrm{M}$ website views per year

At $\mathrm{BMC}$, research is always in progress.

Learn more biomedcentral.com/submission 